\title{
Optimum light transmittance for seed germination and early seedling recruitment of Pinus koraiensis: implications for natural regeneration
}

\author{
Min Zhang ${ }^{(1-2)}$, Qiaoling Yan ${ }^{(1-2)}$, \\ Jiaojun Zhu ${ }^{(1-2)}$
}

\begin{abstract}
Light transmittance regulated by canopy openness influences the microsite conditions for natural regeneration. The successful transition from seed germination to subsequent seedling recruitment (i.e., early seedling survival and growth) determines the natural regeneration potential. However, there is little information on the effect of varying light transmittance on seed germination and seedling recruitment of Pinus koraiensis Siebold \& Zucc. (Korean pine). We aimed to determine the optimum light requirements for this transition process in $P$. koraiensis to propose practical measures for improving its natural regeneration. The transition process was studied under five light transmittance regimes $(100 \%, 60 \%, 30 \%, 15 \%$ and $5 \%$ of full light) over two consecutive years (2010 and 2011). The highest germination percentage in both years occurred at $30 \%$ light transmittance. Generally, mean germination time (MGT) declined with increased light transmittance. Seedling survival exhibited no significant differences between treatments for 1-year-old seedlings, but was higher at $30 \%$ than at $5 \%$ light transmittance for the 2 -year-old seedlings. In contrast, seedling height, root collar diameter and total biomass were highest at $60 \%-100 \%$ light transmittance for both 1- and 2-year-old seedlings. Furthermore, the light transmittance also influenced the growth characteristics of $P$. koraiensis seedlings through regulating MGT. These results suggest that growth of $P$. koraiensis seedling requires a higher light transmittance $(60-100 \%)$ than that required for seed germination, even though $30 \%$ light transmittance was favorable to the earlier emergence with larger specific leaf area. Silvicultural measures such as thinning are recommended to increase light irradiance in the forest understorey with the aim of improving the natural regeneration of $P$. koraiensis.
\end{abstract}

Keywords: Germination, Light Transmittance, Natural Regeneration, Seedling Emergence, Seedling Survival

the original MBKPF (accounting for 52.5\% of Northeast (hina) have been destroyed and replaced by secondary forests (Zhu 2002, Wu et al. 2004). The productivity and ecological functions of secondary forests are much lower than those of the original MBKPF. Specifically, secondary forests are characterized by the disappearance of basic structures and intrinsic functions, including the reduction in biodiversity, stability and ecosystem productivity (Zhu 2002). Increasing the proportion of $P$. koraiensis in the secondary forests, and further development of these MBKPF stands is conside-
(1) State Key Laboratory of Forest and Soil Ecology, Institute of Applied Ecology, Chinese Academy of Sciences, Shenyang 110164 (P.R. China); (2) Qingyuan Forest CERN, Chinese Academy of Sciences, Shenyang 110016 (P.R. China)

@ Jiaojun Zhu (jiaojunzhu@iae.ac.cn)

Received: Jul 10, 2014 - Accepted: Feb 11, 2015

Citation: Zhang M, Yan Q, Zhu J (2015). Optimum light transmittance for seed germination and early seedling recruitment of Pinus koraiensis: implications for natural regeneration. iForest 8: 853-859. - doi: 10.3832/ifor1397-008 [online 2015-05-22]

Communicated by: Gianfranco Minotta red important to promote these ecological and productive functions. However, development of a P. koraiensis component has been severely limited due to its failure in natural regeneration.

To achieve natural regeneration, it is vital to provide abundant seeds, ensure successful seed germination, seedling emergence and survival (Zhu et al. 2003). The successful transition from seed germination to subsequent seedling recruitment (i.e., early seedling survival and growth) determines the regeneration potential for tree species (Hussain et al. 2001). Furthermore, these two key stages are the most sensitive to environmental conditions (e.g., light, temperature and water conditions Kyereh et al. 1999, Ruano et al. 2009) or biotic factors (e.g., animal predation or browsing) in the regeneration processes. Due to the poor palatability of $P$. koraiensis seedlings, browsing pressure is not a factor limiting natural regeneration. However, the environmental requirements can change from the stages of seed germination to seedling recruitment (Figueroa \& Lusk 2001). Therefore, determining the requirements for both these two key stages would be helpful to improve the natural 


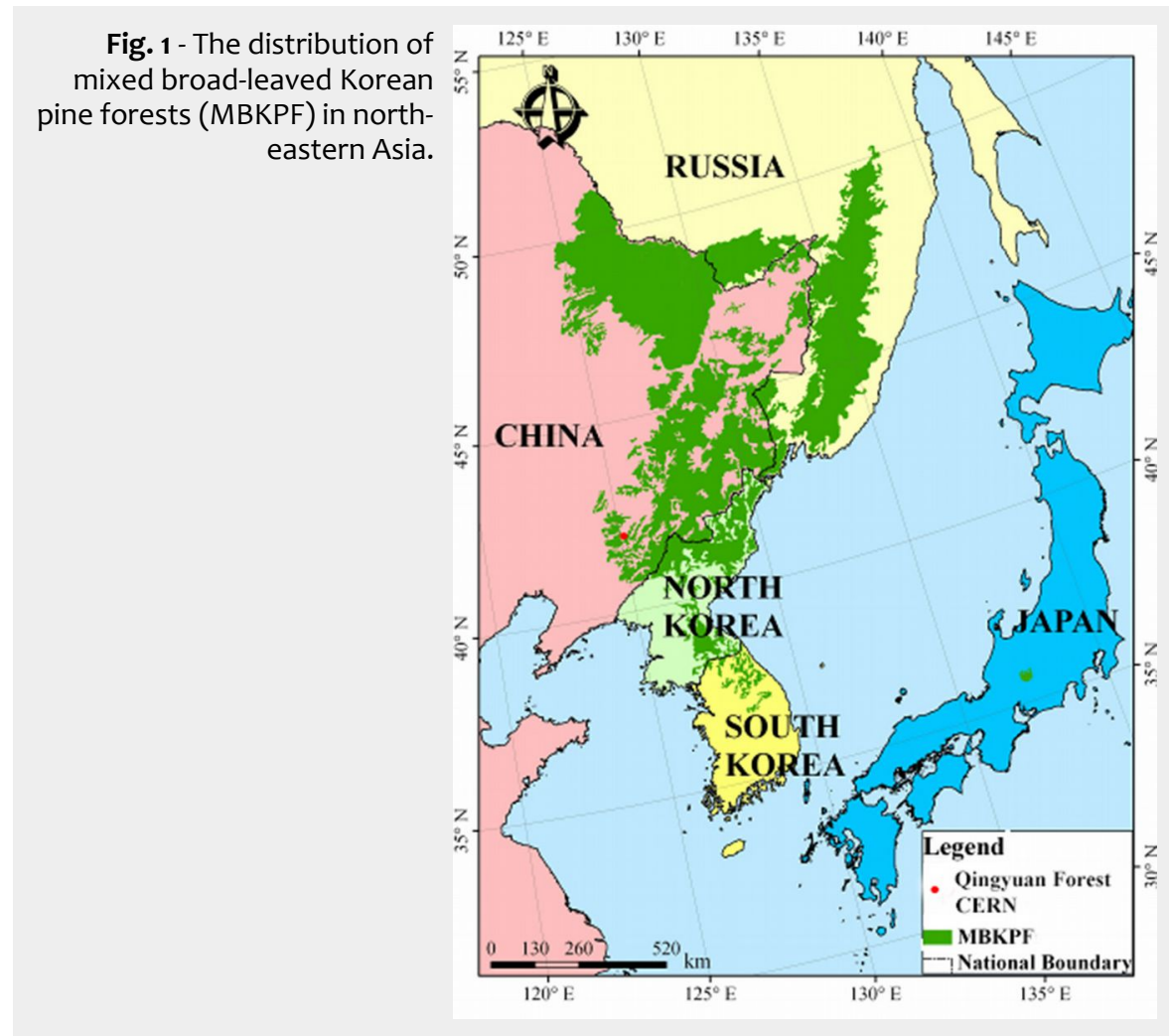

regeneration of $P$. koraiensis.

In silviculture, adjusting the light transmittance to the forest understorey by changing the forest composition and canopy structure is crucial to improve tree regeneration (Pothier \& Prévost 2002, Nocentini 2009). Canopy openness is a characteristics widely analyzed in many studies, since it relates with the light transmission through the canopy (Beaudet \& Messier 2002, Zhu et al. 2003, Chianucci \& Cutini 2012). In temperate deciduous forests, canopy openings caused by natural or human disturbances produce spatial heterogeneity of light regimes in forest understorey (Beaudet \& Messier 2002). In addition, seasonal variation in leaf canopy also contributes greatly to the temporal variability of light conditions under temperate secondary forests (Rich et al. 1993). Consequently, the spatio-temporal variation of light in the understorey plays a critical role in determining patterns of tree regeneration. The opening of a canopy firstly changes the light regimes, and then brings about the variation in temperature, soil moisture, etc. The estimate of light transmittance in the understorey, therefore, represents a wide range of microsite conditions including light, temperature and soil moisture.

Many studies have been published on the response of seed germination or seedling survival/growth of Pinus spp. to different light conditions (Day et al. 2005). In particular, it has been reported that light requirements may differ between seed germination and the subsequent seedling growth. For example, Parker et al. (2006) concluded that both seedling germination and percent emergence were significantly higher under low light ( $13 \%$ of full sunlight) than under moderate light ( $47 \%$ of full sunlight) for Pinus strobus L.; however, moderate light level favored seedling growth in this species (Parker et al. 2004). P. pinea maintained high germination percentages in dark conditions (Ganatsas \& Tsakaldimi 2007), while seedlings required fairly high light irradiance (Fady et al. 2004). P. pinaster exhibited the highest germination percentage and aboveground dry weight in $25 \%$ and $100 \%$ light intensity, respectively (Ruano et al. 2009). Pulinets (1986) studied the development of $P$. koraiensis under different light intensities created by the shading of shrubs, and concluded that the light requirements varied greatly across the entire growth period. Zhang et al. (2012) found that $30 \%$ of the full sunlight was optimum for seed germination of $P$. koraiensis in both shade houses and field conditions. To our knowledge, $60 \%$ of full light was the most favorable environment for the growth of 5-year-old $P$. koraiensis seedlings (Zhu et al. 2014).

Despite the number of studies on the above topic, no reports based on continuous observations have been published with the aim of exploring possible differences in light requirements between seed germination and initial seedling recruitment in P. koraiensis. To quantify the light requirements of these two key stages, seeds of $P$. koraiensis were sowed at five light transmittances (100\%, 60\%, 30\%, 15\% and $5 \%$ of the full light), and emerged seedlings were monitored for two consecutive years. We hypothesized that the light requirements for seedling growth were different from those for seed germination in $P$. koraiensis.

\section{Materials and methods}

\section{Study site}

The study was conducted at the Qingyuan Forest CERN (Chinese Ecosystem Research Network), Chinese Academy of Sciences ( $41^{\circ} 51^{\prime} 06^{\prime \prime} \mathrm{N}, 124^{\circ} 54^{\prime} 33^{\prime \prime} \mathrm{E}, 456-1116$ $\mathrm{m}$ a.s.l.). The climate is a continental monsoon type with a windy spring, a warm, humid summer, and a dry, cold winter. Annual average precipitation in the area is $811 \mathrm{~mm}$ and mean annual air temperature is $4.7^{\circ} \mathrm{C}$ with a maximum $36.5^{\circ} \mathrm{C}$ in July and a minimum $-37.6{ }^{\circ} \mathrm{C}$ in January. The frost-free period lasts 130 days and the growing season ranges from early April to late September (Zhu et al. 2008). The vegetation is representative of the natural secondary forest in this region, dominated by Juglans mandshurica, Phellodendron amurense, Fraxinus mandshurica, Quercus mongolica, and Fraxinus rhynchophylla.

\section{Seed collection and pretreatment}

Fresh seeds of $P$. koraiensis were randomly collected from at least $3(30 \times 30 \mathrm{~m})$ stands with reproductively mature trees at the Qingyuan Forest CERN in late September 2009. All seeds were air-dried from September to November. Then more than 1000 seeds were mixed with wet sand and stratified at low temperatures (between -5 and zero ${ }^{\circ} \mathrm{C}$ ) from November 2009 to April 2010 to break the deep dormancy characteristic of this species. In May 2010, the seeds were soaked in $0.5 \%$ potassium permanganate $\left(\mathrm{K}_{2} \mathrm{MnO}_{4}\right)$ for 30 minutes to sterilize the seed surfaces. Any seeds that sunk immediately were considered as "viable" (Tanaka-Oda et al. 2009), while floating seeds were considered as "non-viable" and then removed. Viable seeds of a similar size were used for the germination experiment in this study.

\section{Experiment design}

Four main seed plots were framed by wooden slats. Each plot was divided into three subplots $(\mathrm{ca} .150 \times 100 \mathrm{~cm}$ ) with a 30 $\mathrm{cm}$ buffer area between the two adjacent subplots (Fig. 2). We assigned different light transmittance to each subplots by using different layers of neutral shading nets above the wooden slats. Each treatment was created by the use of independent shading nets, obtaining 3 replicates of 4 levels of light treatments (60\%,30\%, 15\% and $5 \%$ light transmittance), with full sunlight (100\% light transmittance) as the control, which was also replicated three times. The relative light transmittance in each treatment was calculated by the specific photosynthetic photon flux density (PPFD) with respect to the full sunlight value (Fig. 3). For all the five treatments, the PPFD and topsoil $(0-5 \mathrm{~cm})$ temperature were measured simultaneously using quantum light sensors and temperature probes con- 
nected to a data logger (Watchdog Model 200, Spectrum Technologies, Inc., Plainfield, IL, USA). Data were logged at $15-\mathrm{min}$ intervals on three uninterrupted sunny days (from 07:00 to 18:00 - McLaren \& McDonald 2003) monthly from May to September. Light quality was quantified by averaging the measures from 12:00 to 13:00 on one sunny day (Seiwa et al. 2009) using a different quantum sensor (Skye 110 Red/Far-Red light sensors, Skye instruments Ltd. Llandrindod Wells, Powys, UK). To improve ventilation in the shade houses, a distance of 2-3 centimeters was left between the netting edge and the ground. The relative humidity was monitored by HOBO Pro Model Ho8-032-08 (Onset Computer Corp., Bourne, MA, USA), and considered to be the same in the different shade houses because of the air circulation.

Fifty $P$. koraiensis seeds were sown at a spacing of $3-5 \mathrm{~cm}$ in each light treatment in May 2010. To prevent seed predation by mice or squirrels, all the seeds were sown in plastic pots $(25 \times 30 \mathrm{~cm})$ which were protected by wire netting. The soil used in this experiment was taken from the top soil (o$5 \mathrm{~cm}$ ) of the natural secondary forest at the Qingyuan Forest CERN. Before the experiment, soil was sieved to exclude stones, plant roots and $P$. koraiensis seeds, etc. No fertilizer was applied to the soil. The soil pH was 6.3 (Yang et al. 2013). The number of germinated seeds was recorded every 3-5 days from May to late September (the growth period) over two consecutive years (2010 and 2011), respectively. The germination experiment was terminated once no further germination occurred over a two week period (June 2011- September 2011). Germination date was recorded when the first needle sprout becoming visible (Xiong \& Nilsson 1999, Zhu et al. 2003). Five to ten surviving seedlings in each light transmittance treatment were dug up randomly (every $5^{\text {th }}$ seedling from a random start) in late September 2010 and 2011 respectively, to explore the survival rate, growth state, etc., for 1- and 2-year-old seedlings. Since we did not mark seedlings that emerged in 2010, we assumed that seedlings with relatively larger height and root collar diameter in 2011 could be classified as being two years old. After measuring the growth traits of harvested seedlings (including height, root collar diameter, number of leaves, root length and stem length), each seedling was separated into shoots and roots. These were dried at $90{ }^{\circ} \mathrm{C}$ for $30 \mathrm{~min}$, then at $65^{\circ} \mathrm{C}$ for 24 hours and finally the dry biomass were quantified.

\section{Statistical analysis}

Three parameters (germination percentage, coefficient of germination rate, mean germination time) were used to characterize seed germination. Seven additional parameters (survival rate, seedling height, root collar diameter, total biomass, specific leaf area, leaf area ratio, leaf mass fraction)

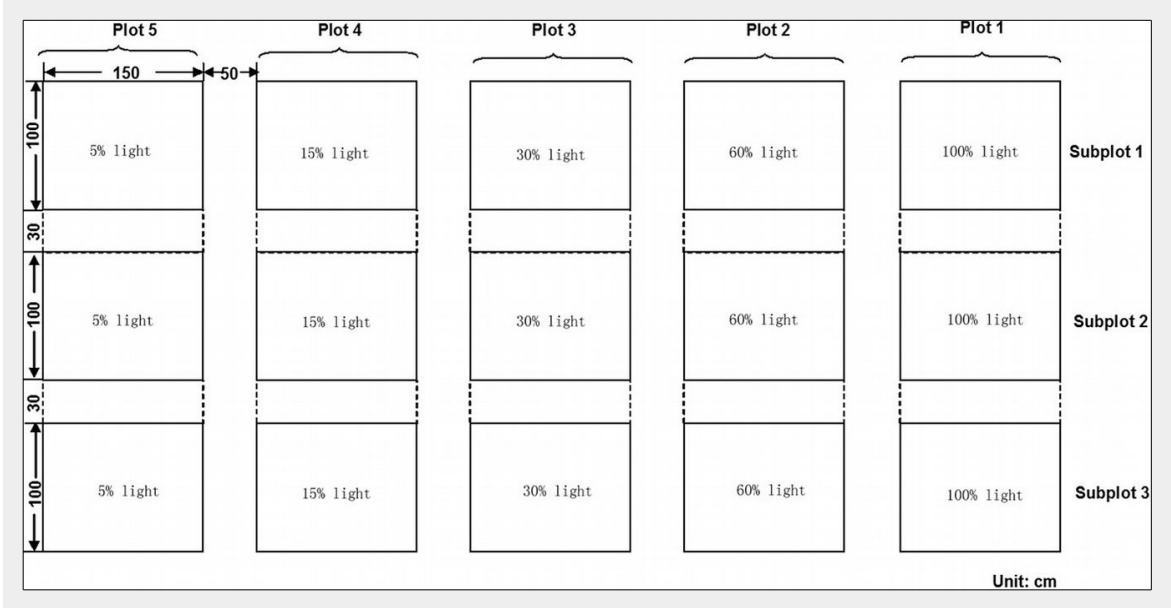

Fig. 2 - Outline of the experimental design.

were used to analyze the seedling survival and survival quality of $P$. koraiensis. The parameters not measured directly were calculated as described below. The germination percentage $(G P)$ was calculated as (eqn. 1):

$$
G P=\frac{S_{N M}}{S_{N O}} \cdot 100
$$

where $S_{\mathrm{NM}}$ is the number of germinated seeds, and $S_{\mathrm{NO}}$ is the number of total experimental seeds (Moya et al. 2013). The mean germination time (MGT) was obtained as (eqn. 2):

$$
M G T=\frac{\sum D N}{\sum N}
$$

where $D$ is the time in days from the sowing date, and $N$ is the number of germinated seeds on a given day (Close \& Wilson 2002). The survival rate $(S R)$ was estimates as (eqn. 3):

$$
S R=\frac{S_{N S}}{S_{N E}} 100
$$

where $S_{\mathrm{NS}}$ is the number of surviving seedlings on a given day, and $S_{\mathrm{NE}}$ is the number of all emerging seedlings from the sowing day. In this study, survival rate was based on data obtained in late September in 2010 and 2011, respectively.

Leaf area $(L A)$ was calculated using the following equation (eqn. 4):

$$
L A=\frac{\pi D L}{5 \sin \left(36^{\circ}\right)}
$$

where $D$ represents the width measured in the middle part of each needle by calipers, and $L$ represents the needle length. Specific leaf area (SLA) was calculated as (eqn. 5):

$$
S L A=\frac{L A}{L M}
$$

where $L M$ is the leaf biomass, and $L A$ is the leaf area, while the leaf area ratio $(L A R)$ was obtained as (eqn. 6):

$$
L A R=\frac{L A}{T B}
$$

where $L A$ is the leaf area, and $T B$ is the total biomass. The leaf mass fraction $(L M F)$ was estimates as follows (eqn. 7):

$$
L M F=\frac{L B}{T B} \cdot 100
$$

where $L B$ is the leaf biomass, and $T B$ is the total biomass.

As suggested by Zuur et al. (2010), a transformation of the response variable

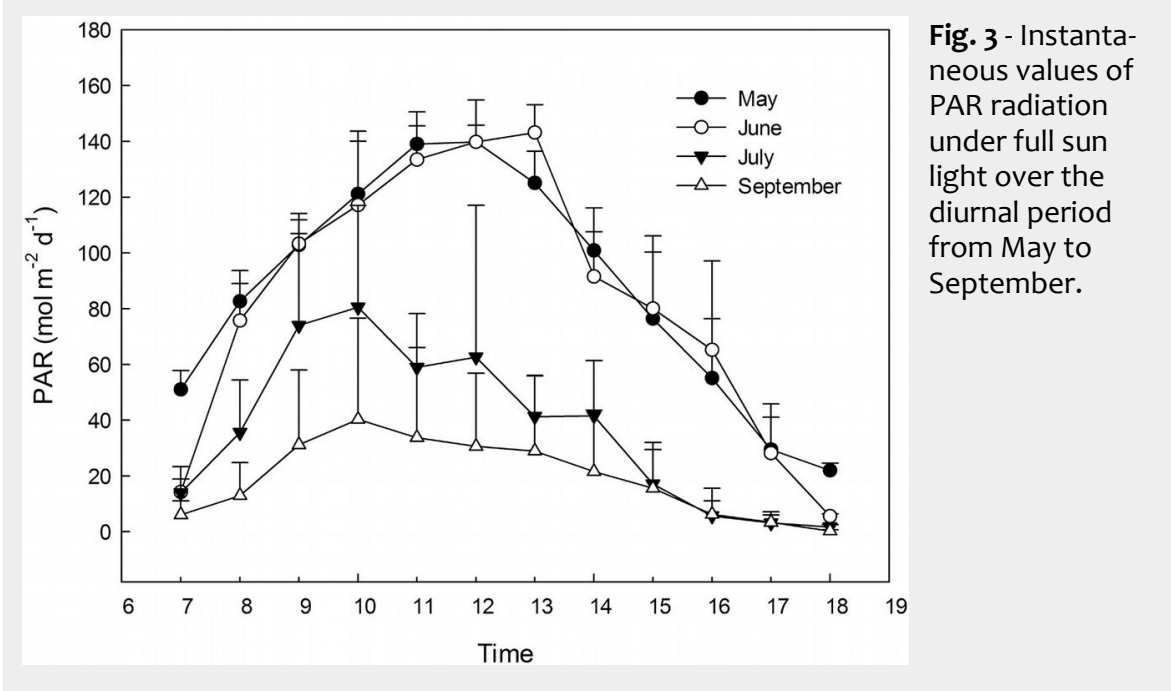


Tab. 1 - Environmental conditions in the shade houses. Different letters indicate significant differences in environment conditions among light treatments.

\begin{tabular}{lcccc}
\hline $\begin{array}{l}\text { Shade } \\
\text { house/site }\end{array}$ & $\begin{array}{c}\text { PAR } \\
\left(\mathrm{mol} \mathrm{m}^{-2} \mathbf{d}^{-1}\right)\end{array}$ & $\begin{array}{c}\text { Red/Far Red } \\
\text { ratio }\end{array}$ & $\begin{array}{c}\text { Topsoil } \\
\text { temperature } \\
\left({ }^{\circ} \mathrm{C}\right)\end{array}$ & $\begin{array}{c}\text { Air humidity } \\
(\%)\end{array}$ \\
\hline $100 \%$ & $60.60 \pm 10.66$ & $1.11 \pm 0.003^{\mathrm{a}}$ & $24.75 \pm 0.53^{\mathrm{b}}$ & $71 \pm 3.8^{\mathrm{a}}$ \\
$60 \%$ & $39.70 \pm 6.76$ & $1.10 \pm 0.005^{\mathrm{a}}$ & $23.17 \pm 0.49^{\mathrm{b}}$ & $62 \pm 9.3^{\mathrm{a}}$ \\
$30 \%$ & $20.15 \pm 3.11$ & $1.10 \pm 0.002^{\mathrm{a}}$ & $20.75 \pm 0.51^{\mathrm{a}}$ & $69 \pm 10.5^{\mathrm{a}}$ \\
$15 \%$ & $11.15 \pm 2.60$ & $1.09 \pm 0.002^{\mathrm{a}}$ & $20.33 \pm 0.53^{\mathrm{a}}$ & $80 \pm 4.8^{\mathrm{a}}$ \\
$5 \%$ & $5.83 \pm 1.39$ & $1.08 \pm 0.003^{\mathrm{a}}$ & $19.92 \pm 0.24^{\mathrm{a}}$ & $79 \pm 11.0^{\mathrm{a}}$ \\
\hline
\end{tabular}

Fig. 4 - Germination percentages of $\mathrm{Pi}$ nus koraiensis under different light transmittances. Different letters indicate significant differences in germination percentage along the light transmittances $(P \leq 0.05)$. The black and white column represents the cumulative germination percentage in the first year (2010) and the second year (2011), respectively.

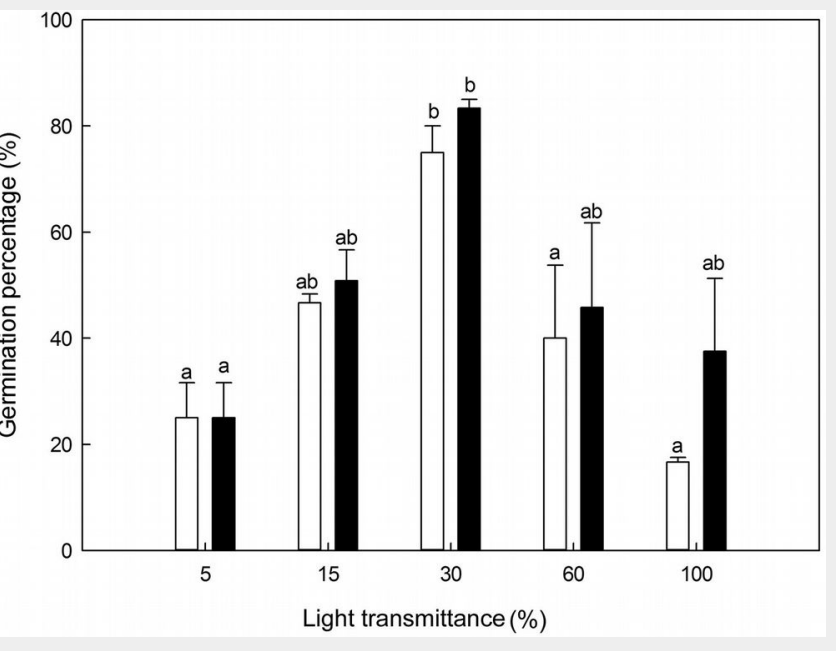

Fig. 5 - Mean germi nation time (MGT) of Pinus koraiensis under different light transmittances for 2 year-old seedlings.

Different letters indicate significant dif

ferences in $M G T$ along the light transmittances $(P \leq 0.05)$.

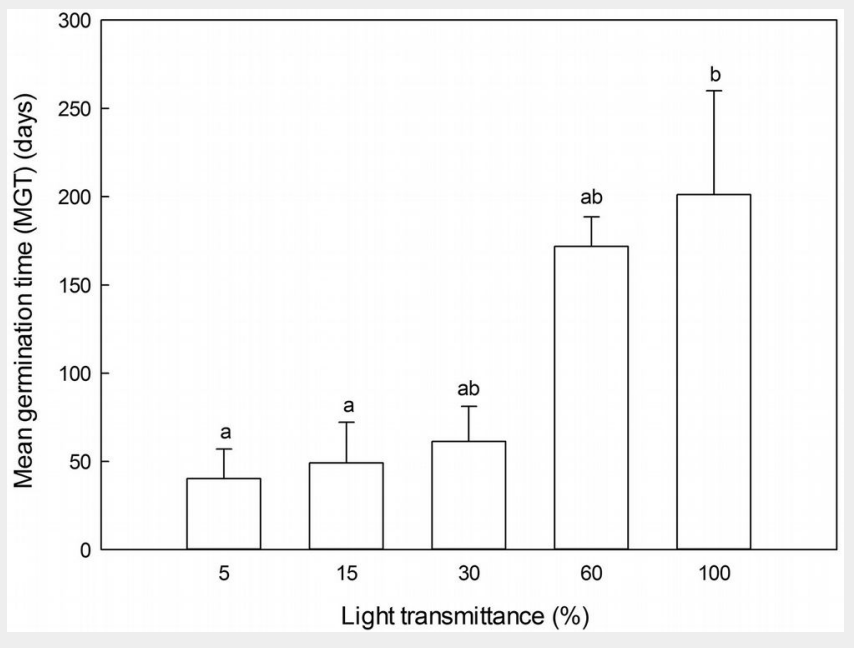

Fig. 6 - Survival rates of Pinus koraiensis seedlings under different light transmittances. Different letters indicate significant differences in survival rate along the light transmittances $(P \leq 0.05)$. The white and black column represents the survival rate for $1-$ and 2-year-old seedlings, respectively.

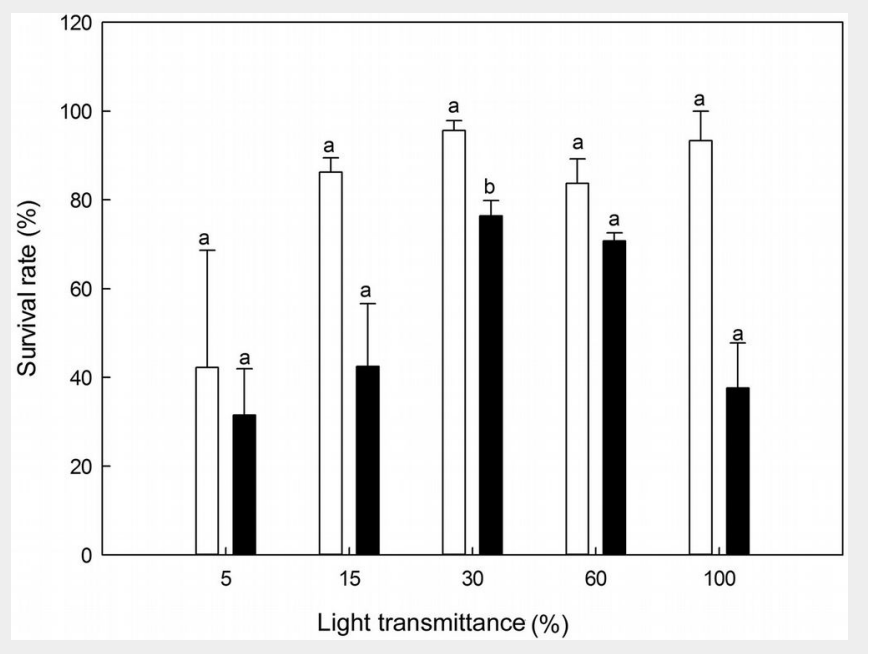

should be applied when departure from normal distribution or heterogeneity of variance occur. Using normal probability plots, percentage data (i.e., germination percentage, survival rate) was tested for normality, and germination data was transformed as arcsine-square-root to meet the assumptions of ANOVA (Ren \& Tao 2004, Seiwa et al. 2009). Post-hoc Tukey's test was applied using the SPSS ${ }^{\circledR}$ v. 16 software package (SPSS Inc., Chicago, IL, USA) to ascertain the significance of differences in seed germination for the two years and seedling survival/growth across the different light transmittance regimes for 1-yearold seedlings. The non-parametric MannWhitney test was applied to $S L A$ data to overcome their departure from normality. To exclude the confounding effect of morphology in the first year, a covariance analysis (ANCOVA - South et al. 1989) with light as the fixed factor and morphology values of 1-year-old seedlings as the covariate factor was conducted for 2-year-old seedlings. A backwards multiple regression was carried out to quantify the contributions of light transmittance and $M G T$ to 1- and 2year-old seedling growth characteristics, including seedling height, root collar diameter $(R C D)$, total biomass, specific leaf area $(S L A)$, leaf area ratio $(L A R)$, and leaf mass fraction $(L M F)$. SLA, LAR and $L M F$ were plotted against the light transmittance, respectively. Differences obtained at a level of $P \leq 0.05$ were considered significant.

\section{Results}

\section{Internal environmental conditions in} shade houses

In all the five light transmittance regimes, the topsoil temperature varied significantly (Tab. 1). However, the topsoil temperature exhibited no significant differences from $100 \%$ to $60 \%$ light transmittance, and from $30 \%$ to $5 \%$ light transmittance. The Red/Far Red ratio and air humidity did not vary between the five treatments (Tab. 1).

\section{Effects of light transmittance on seed germination}

The germination percentage of $P$. koraiensis was significantly affected by the light transmittance in the two years (ANOVA: $F=9.64, P<0.01$ in 2010; $F=3.40, P=0.05$ in 2011 - Fig. 4). The germination percentage was slightly higher in the second year than in the first year under all the light transmittance regimes. In both years, the germination percentage was the highest at $30 \%$ light transmittance, while the lowest was found at $100 \%$ (the first year) and 5\% light transmittance (the second year), respectively.

$M G T$ was the highest in full sunlight and declined with decreasing light transmittance, with no significant differences among the four lower light transmittance regimes (Fig. 5). 
Effects of light transmittance on early seedling recruitment

No significant differences in survival were found among the five light transmittance treatments for 1-year-old seedlings (ANOVA: $F=2.91, P>0.05$ - Fig. 6). However, 30\% light transmittance showed significantly higher survival rates along the light levels for 2-year-old seedlings (ANCOVA: $F=4.87$, $P=0.03$ - Fig. 6). Overall, the survival rates of all the treatments were seemingly lower for 2-year-old seedlings than for 1-year-old seedlings. Compared to 1-year-old seedlings, 2-year-old seedlings exhibited significantly lower survival rates $(P<0.05)$ at 30\% and $15 \%$ light transmittance (Fig. 6 ).

Seedling height of $P$. koraiensis increased with age (ANOVA: $F=10.63, P<0.001$ for 1 year-old seedlings; ANCOVA: $F=10.82$, $P<0.001$ for 2-year-old seedlings - Fig. 7). It was significantly higher in $100 \%$ light transmittance regime for 1-year-old seedlings and in $60-100 \%$ light transmittance regimes for 2-year-old seedlings (Fig. 7). Generally, the root collar diameter of $P$. koraiensis seedlings was significantly larger at $100 \%$, $60 \%$ and $30 \%$ light transmittance, though decreased slightly at $15 \%$ and $5 \%$ light transmittance with seedling age (ANOVA: $F=4.27, \quad P<0.01$ for 1-year-old seedlings; ANCOVA: $F=11.28, P<0.001$ for 2-year-old seedlings - Fig. 7). The largest root collar diameter was always recorded in the $100 \%$ light transmittance treatment (Fig. 7).

There were significant differences in biomass between $100 \%$ light transmittance and the other treatments for 1-year-old $P$. koraiensis seedlings (ANOVA: $F=14.03$, $P<0.01$ ). Light irradiance (univariate analysis: $F=7.38, P=0.03$ ) and the interaction between light and biomass in the first year (univariate analysis: $F=6.91, P=0.03$ ) jointly affected the biomass accumulation pattern in the second year. For 2-year-old seedlings, biomass at the $60 \%$ and $100 \%$ light transmittance was significantly higher as compared with the other three light regimes (Fig. 8).

For 1-year-old seedlings, a significant logistic relationship was determined between the SLA and the light transmittance $\left(S L A_{1}=91.14-6.15 \cdot \ln (\right.$ Light $)$, $\left.R^{2}=0.854, P<0.05\right)$. A significant linear correlation was found between $L A R$ and light transmittance for the 1-year-old seedlings $\left(L A R_{1}=2.76-0.01 \cdot\right.$ Light, $R^{2}=0.904$, $P<0.05)$, and between $L M F$ and light transmittance for both ages of seedlings $\left(L M F_{1}\right.$ $=0.51-0.0008 \cdot$ Light, $R^{2}=0.749, P<0.10$; $L M F_{2}=0.499-0.001 \cdot$ Light, $R^{2}=0.916$, $\mathrm{P}<0.05)$.

\section{Contributions of light transmittance and germination parameters on seedling performance}

Except for the $S L A$, all the characteristics of 1- and 2-year-old seedlings can be explained by light transmittance, $M G T$, or a combination of them (Tab. 2). For 1-year-old plants, seedling height, root collar diameter, $L A R$ and $L M F$ were all significantly
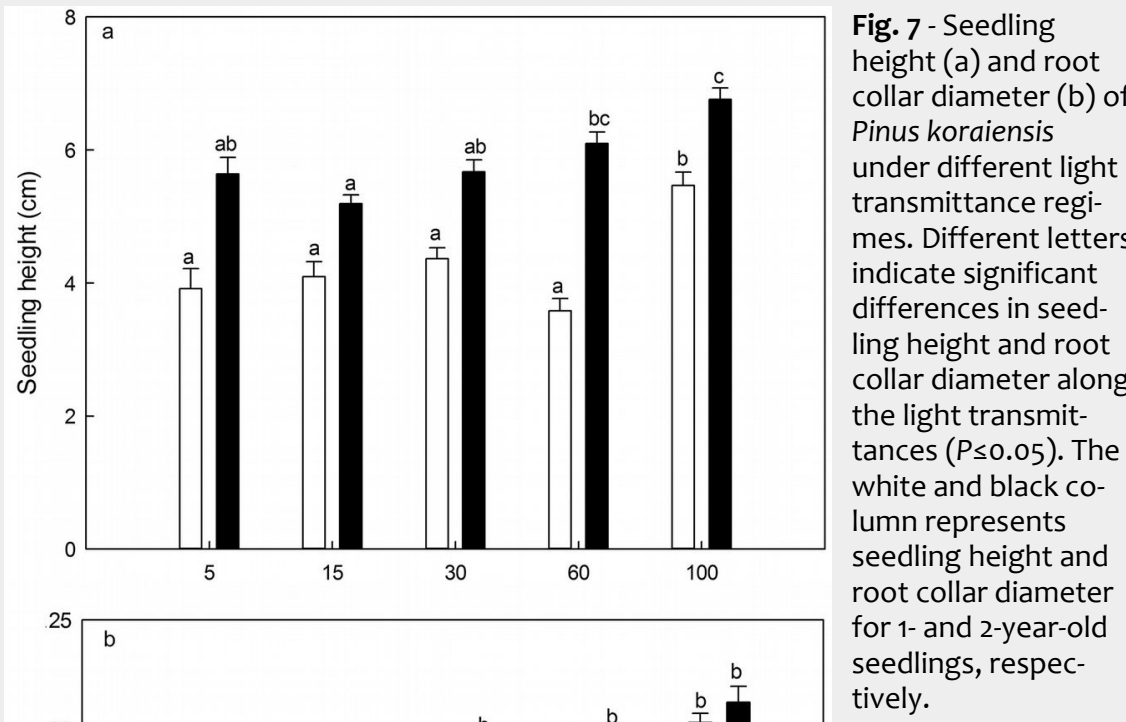

Fig. 7 - Seedling height (a) and root collar diameter (b) of Pinus koraiensis under different light transmittance regimes. Different letters indicate significant differences in seedling height and root collar diameter along the light transmittances $(P \leq 0.05)$. The white and black column represents seedling height and root collar diameter for 1- and 2-year-old tively.
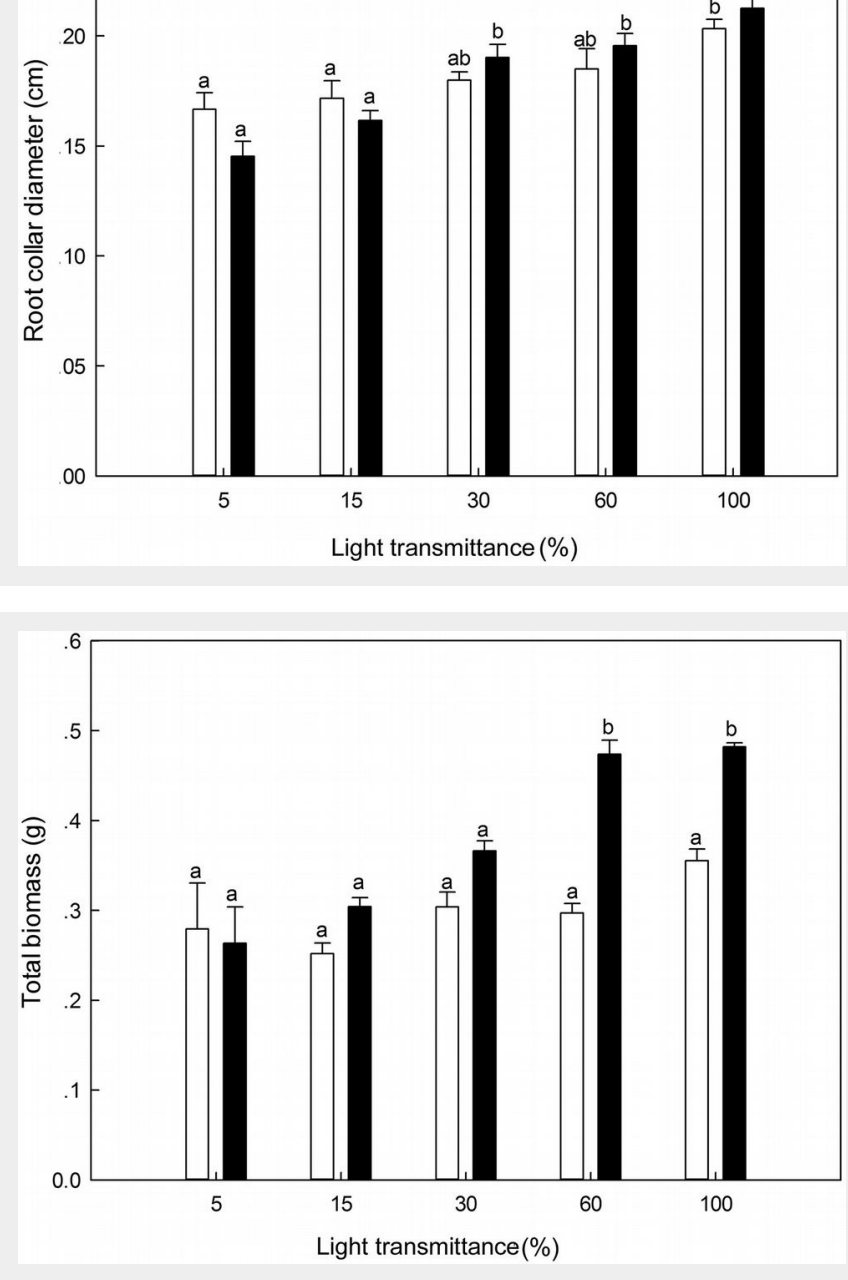

Fig. 8 - Total biomass of Pinus koraiensis under different light transmittance regimes. Different letters indicate significant differences in total biomass along the light transmittances $(P \leq 0.05)$. The white and black column represents the total biomass for 1- and 2year-old seedlings, respectively.

Tab. 2 - Effects of light transmittance and mean germination time (MGT) on 1- and 2year-old seedling growth characteristics. The standardized coefficients of the back wards multiple regression are shown for variables which contributed significantly to the model. Values outside and inside the brackets represented the data obtained for 1- and 2-year-old seedlings, respectively. (-): no observation; ( $\left.{ }^{*}\right)$ : $P<0.05 ;(+)$ : $P<0.10$.

\begin{tabular}{lcll}
\hline Variables & Light transmittance & \multicolumn{1}{c}{$\boldsymbol{M G T}$} & \multicolumn{1}{c}{$\boldsymbol{R}^{2}$} \\
\hline Seedling height $(S H)$ & $3.08^{*}(-)$ & $-2.52^{+}\left(0.93^{*}\right)$ & $0.92^{*}\left(0.87^{*}\right)$ \\
Root collar diameter $(R C D)$ & $1.51^{*}\left(0.92^{*}\right)$ & $-0.54^{*}(-)$ & $0.99^{*}\left(0.84^{*}\right)$ \\
Total biomass $(T B)$ & $0.88^{*}(-)$ & $-\left(0.96^{*}\right)$ & $0.78^{*}\left(0.91^{*}\right)$ \\
Specific leaf area $(S L A)$ & $-(-)$ & $-(-)$ & $-(-)$ \\
Leaf area ratio $(L A R)$ & $-1.99^{*}\left(1.59^{*}\right)$ & $1.09^{*}\left(-2.42^{*}\right)$ & $0.99^{*}\left(0.99^{*}\right)$ \\
Leaf mass fraction $(L M F)$ & $-2.50^{*}(-)$ & $-1.70^{+}\left(-0.96^{*}\right)$ & $0.97^{*}\left(0.92^{*}\right)$ \\
\hline
\end{tabular}


related to the combination of light trans mittance and $M G T$, while total biomass was only related to light transmittance. Fo the 2-year-old seedlings, height, total biomass and $L M F$ were significantly related to $M G T$, and $R C D$ was significantly related to the light transmittance, while $L A R$ was related to the combination of light trans mittance and $M G T$. For $L A R$ and $L M F$, light transmittance and $M G T$ could explain more than $90 \%$ of their variances for 1 - and 2-year-old seedlings.

\section{Discussion}

\section{Light requirements for seed}

germination of $P$. koraiensis

The germination percentage in both years was the highest at 30\% light transmit tance. The results showed the same response to light transmittance in both years, demonstrating that light levels play a critical role in seed germination. According to our field observations, 30\% light transmittance occurred in broadleaved se condary forest stands in the early spring prior to leaf expansion (see Fig. 1 in Zhang et al. 2012). Thus, early spring seem a favorable period for seed germination of $P$ koraiensis. This result clearly confirms the findings of our previous field experiment (Zhang et al. 2012), in which $80 \%$ of $P$. koraiensis seeds germinated prior to leaf expansion.

The $M G T$ s of $P$. koraiensis were also affec ted by light transmittance. According to previous reports (Pons 1992, Silvertown \& Doust 1993), it is advantageous for plants to initiate germination when conditions are favorable for seedling survival. However, the optimum conditions for seedling growth might not correspond to those for seed germination and seedling survival. Indeed, our results indicated that the full sunlight favors the seedling growth, whereas it prolongs the mean germination time and slows down the germination rate. The different germination percentages in two light regimes with similar temperature and moisture conditions (Tab. 1, Fig. 4), 30\% and $5 \%$ light transmittance, emphasized that there were significant effects of light on seed germination of $P$. koraiensis. Furthermore, compared with full sunlight conditions, shading could play a critical role in increasing germination percentage, and shortening the germination time. In sum mary, 30\% light transmittance was the optimum light condition for seed germination in $P$. koraiensis, with the highest germination percentage and a relatively fast germination rate (lower values of $M G T$ ).

Light requirements for seedling survival and growth of $P$. koraiensis

In this study, no significant differences in survival rate were found for the 1-year-old seedlings (Fig. 6), suggesting that $P$. koraiensis seedlings had a wide plasticity at the earliest stage, allowing their acclimation to different light transmittance regi- mes. However, 30\% light transmittance had the highest survival rate for the 2-year-old seedlings, indicating similar light requirements for both seedling survival and seed germination of $P$. koraiensis. Carbohydrates are critical for maintaining the metabolism and provide a buffer for $P$. koraiensis seedlings under stressful conditions (Zhang et al. 2013). Thus, the overall lower survival rates for 2-year-old seedlings than for 1year-old seedlings might reflect a lag effect of $P$. koraiensis seedlings to different light irradiance. Morphologically, 60\%-100\% light transmittance was the optimum level for seedling height, root collar diameter and total biomass of $P$. koraiensis seedlings (Fig. 7, Fig. 8). This is supported by the finding that the light-saturated photosynthetic rates in $60 \%$ and $100 \%$ treatments were higher than those in other light treatments for 5-year-old seedlings (Zhu et al. 2014). Furthermore, as a response to shadier conditions, the largest SLA, LAR and $L M F$ were found in $5 \%$ light transmittance to maximize the light capture.

There was a discrepancy between the best light conditions for seed germination/ seedling survival (30\% light transmittance) and those for seedling growth $(60 \%-100 \%$ light transmittance). This is due to the trade-off between carbon allocation for growth and for storage and defense (Poorter \& Kitajima 2007). In the lowest light transmittance regime (5\%), more carbon was allocated to seedling defense and storage resulting in the overall highest survival rate. However, at the $60 \%$ or $100 \%$ light transmittance levels, more carbon was allocated to seedling growth than to defense or storage.

Implications on light requirements for seed germination and early seedling growth of $P$. koraiensis

In this study, the interaction of light and $M G T$ influence the growth of 1- and 2-yearold seedlings, as revealed by the regression analysis carried out (Tab. 2). Seedlings emerging from different light transmittance regimes may be influenced by both the abiotic (e.g., light) and biotic (e.g., $M G T$ in the present study) factors (Noe \& Zedler 2001). MGT was reported to have a negative relationship with seedling size, i.e., later germinating seeds produce smaller seedlings (Demir et al. 2008). In this study, we also found negative relationships between $M G T$ and the height and root collar diameter of 1-year-old seedlings. Overall, seed germination/seedling survival rate and seedling growth showed different response functions to light transmittance. Seed germination in response to light had a peak value at 30\% light transmittance, while seedling height, root collar diameter and total biomass were greater with increased light. This implied that the light requirements of $P$. koraiensis were higher for seedling growth than for seed germination. Such uncoupled light requirements have also been reported for other tree species which can germinate under closed canopy, but need higher light at the seedling stage (Kyereh et al. 1999, Fady et al. 2004, Parker et al. 2004, 2006, Ganatsas \& Tsakaldimi 2007). Moreover, the germination of most seeds of $P$. koraiensis occurs in early spring before leaf expansion in the secondary forest (Zhang et al. 2012). The subsequent reduction in light transmittance after leaf expansion would be disadvantageous to seedling growth of $P$. koraiensis. The distinct light requirements for seed germination and seedling growth of $P$. koraiensis would be a major factor hampering its natural regeneration, strongly supporting our hypothesis in the present study. Therefore, to improve the natural regeneration of $P$. koraiensis in the secondary forest understorey, disturbances (e.g., thinning) should be applied to allow more light reaching the understorey layer.

\section{Conclusions}

Light requirements increased from 30\% to $60-100 \%$ light transmittance during the transition from seed germination to seedling recruitment in $P$. koraiensis. The germination characteristics (i.e., $M G T$ ) showed a coupling effect with light transmittance on the subsequent pine seedling growth. However, the highest $M G T$ in P. koraiensis was observed at 30\% light transmittance, which is not the best light regime for seedling growth. There might be a hindrance for the natural regeneration process of $P$. koraiensis resulting from the decreased light transmittance after leaf expansion in the growing season, contrasting with the elevated light requirement for growth. Therefore, disturbances such as gap openings or thinnings are strongly recommended as an operational measure to enlarge canopy openness in temperate secondary forests and improve the natural regeneration of $P$. koraiensis.

\section{Acknowledgements}

Min Zhang contributed to the experimental design, carried out the experiment, and analyzed the data; she also shared in writing the manuscript. Qiaoling Yan contributed to the design of the experiment and helped to revise the manuscript. Jiaojun Zhu contributed to the design of the experiment, helped to write the manuscript, supervised the work and coordinated the research project.

We would like to thank Dehui Zeng, Kai Yang, Lizhong Yu, Miao Wang, Jinxin Zhang and Zhanqing Hao for their constructive suggestions about this study. Thanks are also due to Qun Gang, Wenwu Ji and De'an Zheng for their field work.

This research was supported by the $\mathrm{Na}$ tional Natural Science Foundation of China (contract no. 31330016 and 30830085).

\section{References}

Beaudet M, Messier C (2002). Variation in canopy openness and light transmission following selection cutting in Northern hardwood 
stands: an assessment based on hemispherical photographs. Agricultural and Forest Meterology 110: 217-228. - doi: 10.1016/S0168-1923(01) 00289-1

Chianucci F, Cutini A (2012). Digital hemispherical photography for estimating forest canopy properties: current controversies and opportunities. iForest 5: 290-295. - doi: 10.3832/iforo775005

Close DC, Wilson SJ (2002). Provenance effects on pre-germination treatments for Eucalyptus regnans and E. delegatensis seed. Forest Ecology and Management 170: 299-305. - doi: 10.101 6/S0378-1127(01)00768-X

Day ME, Schedlbauer JL, Livingston WH, Greenwood MS, White AS, Brissette JC (2005). Influence of seedbed, light environment, and elevated night temperature on growth and carbon allocation in pitch pine (Pinus rigida) and jack pine (Pinus banksiana) seedlings. Forest Ecology and Management 205: 59-71. - doi: 10.1016/j. foreco.2004.10.004

Demir I, Ermis S, Mavi K, Matthews S (2008). Mean germination time of pepper seed lots (Capsicum annuum L.) predicts size and uniformity of seedlings in germination tests and transplant modules. Seed Science and Technology 36: 21-30. - doi: 10.15258/sst.2008.36.1.02

Fady B, Fineschi S, Vendramin GG (2004). EUFORGEN Technical guidelines for genetic conservation and use for Italian stone pine (Pinus pinea). International Plant Genetic Resources Institute, Rome, Italy, pp. 6. [online] URL: http://books.google.com/books?id=Z5AhkIWzie oC

Figueroa JA, Lusk CH (2001). Germination requirements and seedling shade tolerance are not correlated in a Chilean temperate rain forest. New Phytologist 152: 483-489. - doi: 10.104 6/j.0028-646X.2001.00282.x

Ganatsas PP, Tsakaldimi MN (2007). Effect of light conditions and salinity on germination behaviour and early growth of umbrella pine (Pinus pinea L.) seed. Journal of Horticultural Science and Biotechnology 82 (4): 605-610. [online] URL: http://www.researchgate.net/pro file/Marianthi_Tsakaldimi/publication/23409256 6

Guo LP, Ji LZ, Zhang WD, Zhang Y, Xue JG (2010). Forest recovery state in wind disaster area of Changbai Mountains, Northeast China. Chinese Journal of Applied Ecology 21 (6): 1381-1388. [in Chinese with English abstract]

Hussain M, Kubiske ME, Connor KF (2001). Germination of $\mathrm{CO}_{2}$-enriched Pinus taeda $\mathrm{L}$. seeds and subsequent seedling growth responses to $\mathrm{CO}_{2}$ enrichment. Functional Ecology 15: 344350. - doi: 10.1046/j.1365-2435.2001.00521.x

Kyereh B, Swaine MD, Thompson J (1999). Effect of light on the germination of forest trees in Ghana. Journal of Ecology 87 (5): 772-783. - doi: 10.1046/j.1365-2745.1999.00386.x

Ma JL, Zhuang LW, Chen D, Li JW (1992). The geographic distribution of Pinus koraiensis. Journal of Northeast Forestry University 20 (5): 40-48. [in Chinese]

McLaren KP, McDonald MA (2003). The effects of moisture and shade on seed germination and seedling survival in a tropical dry forest in Jamaica. Forest Ecology and Management 183: 61-75. - doi: 10.1016/S0378-1127(03)00100-2
Moya D, De Las Heras, Salvatore R, Valero E, Leone V (2013). Fire intensity and serotiny: response of germination and enzymatic activity in seeds of Pinus halepensis Mill. from southern Italy. Annals of Forest Science 70: 49-59. - doi: 10.1007/s13595-012-0236-x

Nocentini S (2009). Structure and management of beech (Fagus sylvatica L.) forests in Italy. iForest 2: 105-113. - doi: 10.3832/iforo499-002

Noe GB, Zedler JB (2001). Spatio-temporal variation of salt marsh seedling establishment in relation to the abiotic and biotic environment. Journal of Vegetation Science 12 (1): 61-74. - doi: $10.2307 / 3236674$

Parker WC, Noland TL, Morneault EA (2004). Effect of seed mass on early seedling growth of five eastern white pine (Pinus strobus L.) families under contrasting light environments. Canadian Journal of Botany 82 (1): 1645-1655. doi: 10.1139/bo4-129

Parker WC, Noland TL, Morneault EA (2006). The effects of seed mass on germination, seedling emergence, and early seedling growth of eastern white pine (Pinus strobus L.). New forests 32: 33-49. - doi: 10.1007/s11056-005-3391-1

Pons TL (1992). Seed responses to light. In: "Seeds-the ecology of regeneration in plant communities" (Fenner $M$ ed). CAB international, Wallingford, UK, pp. 259-284. [online] URL: http://books.google.com/books?id=wu5JLxbYZ JMC

Poorter L, Kitajima K (2007). Carbohydrate storage and light requirements of tropical moist and dry forest tree species. Ecology 88 (4): 10001011. - doi: 10.1890/06-0984

Pothier D, Prévost M (2002). Photosynthetic light response and growth analysis of competitive regeneration after partial cutting in a boreal mixed stand. Trees 16: 365-373. - doi: 10.1007/s00468-001-0158-y

Pulinets MP (1986). The influence of light intensity on the growth of Pinus koraiensis. Lesnoe Khozyaistvo 4: 40-42.

Ren H, Lu HF, Wang J, Liu N, Guo QF (2012). Forest restoration in China: advances, obstacles, and perspectives. Tree and Forestry Science and Biotechnology 6: 7-16. [online] URL: http://www.admin.forestthreats.org/products/ publications/Forest restoration in China.pdf Ren J, Tao L (2004). Effects of different pre-sowing seed treatments on germination of $10 \mathrm{Cal}$ ligonum species. Forest Ecology and Management 195: 291-300. - doi: 10.1016/j.foreco.2004.0 1.046

Rich P, Clark DB, Clark DA, Oberbauer SF (1993). Long-term study of solar radiation regimes in a tropical wet forest using quantum sensors and hemispherical photography. Agricultural and Forest Meteorology 65: 107-127. - doi: 10.1016/ 0168-1923(93)90040-O

Ruano I, Pando V, Bravo F (2009). How do light and water influence Pinus pinaster Ait. germination and early seedling development? Forest Ecology and Management 258: 2647-2653. - doi: 10.1016/j.foreco.2009.09.027

Seiwa K, Ando M, Imaji A, Tomita M, Kanou K (2009). Spatio-temporal variation of environmental signals inducing seed germination in temperate conifer plantations and natural hardwood forests in northern Japan. Forest Ecology and Management 257: 361-369. - doi: 10.1016/j.foreco.2008.09.002

Silvertown JW, Doust L (1993). Introduction to plant population biology. Blackwell, London, UK, pp. 122-152.

South DB, Larsen HS, Williams HM, Boyer JN (1989). Use of seedling size as a covariate for root growth potential studies. In: Proceedings of the " 5 th Biennial Southern Silvicultural Research Conference" (Miller J ed). New Orleans (LA, USA), 1-3 Nov 1988. Memphis, TN, USA, pp. 89-93. [online] URL: http://www.nurserycoop. auburn.edu/PDFfiles/covariate.pdf

Tanaka-Oda A, Tanaka K, Fukuda K (2009). Optimal germination condition by sulfuric acid pretreatment to improve seed germination of Sabina vulgaris Ant. Journal of Forest Research 14: 251-256. - doi: 10.1007/s10310-009-0129-5 Wu XP, Zhu B, Zhao SQ, Piao SL, Fang JY (2004). Comparison of community structure and species diversity of mixed forests of deciduous broad-leaved tree and Korean pine in Northeast China. Biodiversity Science 12 (1): 174-181. [in Chinese with English abstract] [online] URL: http://europepmc.org/abstract/cba/399815

Xiong SJ, Nilsson C (1999). The effects of plant litter on vegetation: a meta-analysis. Journal of Ecology 89: 984-994. - doi: 10.1046/j.1365-2745. 1999.00414.x

Yang K, Zhu JJ, Shi W (2013). The impact of secondary forests conversion into larch plantations on soil chemical and microbiological properties. Plant and Soil 368 (1-2): 535-546. - doi: 10.1007/s11104-012-1535-6

Zhang M, Zhu JJ, Yan QL (2012). Seed germination of Pinus koraiensis in response to light regimes caused by shading and seed positions. Forest Systems 21: 426-438. - doi: $10.5424 / \mathrm{fs} / 20$ 12213-02721

Zhang M, Zhu JJ, Li MC, Zhang GQ, Yan QL (2013). Different light acclimation strategies of two coexisting tree species seedlings in a temperate secondary forest along five natural light levels. Forest Ecology and Management 306: 234-242. - doi: 10.1016/j.foreco.2013.06.031

Zhu JJ (2002). A review on fundamental studies of secondary forest management. Chinese Journal of Applied Ecology 13 (12): 1689-1694. [in Chinese with English abstract]

Zhu JJ, Matsuzaki T, Li FQ, Gonda Y (2003). Effect of gap size created by thinning on seedling emergency, survival and establishment in a coastal pine forest. Forest Ecology and Management 182 (1-3): 339-354. - doi: 10.1016/S03781127(03)00094-X

Zhu JJ, Liu ZG, Wang HX, Yan QL, Fang HX, Hu LL, Yu LL (2008). Effects of site preparation on emergence and early establishment of Larix olgensis in montane regions of northeastern China. New Forests 36 (3): 247-260. - doi: 10.1007/s11056-008-9097-4

Zhu JJ, Wang K, Sun YR, Yan QL (2014). Response of Pinus koraiensis seedling growth to different light conditions based on the assessment of photosynthesis in current and one-year-old needles. Journal of Forestry Research 25 (1): 5362. - doi: 10.1007/s11676-014-0432-7

Zuur AF, leno EN, Elphick CS (2010). A protocol for data exploration to avoid common statistical problems. Methods in Ecology and Evolution 1: 3-14. - doi: 10.1111/j.2041-210X.2009.0000 1.x 